\title{
Prevention of Rheumatic Fever and Rheumatic Heart Diseases in Bangladesh
}

\author{
Prof. Dr. K.M.H.S. Sirajul Haque \\ Ex-Director, National Centre for Control of Rheumatic Fever \& Heart Diseases, Dhaka, Former \\ Chairman-Department of Cardiology, Ex-Dean- Faculty of Medicine, Bangabandhu Sheikh Mujib \\ Medical University, Dhaka
}

(Cardiovasc. j. 2019; 11(2): 91-92)

Rheumatic Fever (RF) is diagnosed clinically by Jones Criteria with some exceptions of recurrent $\mathrm{RF}$, chorea and Insidious onset carditis. Diagnosis is supported by evidence of streptococcal infection, like visualization of Gram Positive cocci in throat swab Gram staining, isolation of $G A B H$ Streptococcus in throat swab cultures and serological evidence of Streptococcus infection like ASO titre and Anti DNA-ase B. A number of cases of acute $\mathrm{RF}$ present as carditis with heart failure whereas cases progressing to chronic RF present with valvular involvement: mitral stenosis, mitral regurgitation, aortic stenosis and aortic regurgitation with or without associated heart failure.

Prevalence of rheumatic heart disease (RHD) and incidence of acute RF is more in developing countries where there is overcrowding, poor nutrition, poverty and poor hygienic practices. In Bangladesh, prevalence of RF \& RHD was 7.5/1000 in the '70s and came down to $4 / 1000$ by the '90s. More recent studies show that the prevalence of RF/RHD was brought down to 0.9/1000 in 2015 .

Realizing the magnitude of the problem, Ministry of Health and Family Welfare (MOHFW), People's Republic of Bangladesh, took up a Pilot Project in the National Institute of Cardiovascular Diseases (NICVD), Sher-EBangla Nagar-Dhaka in 1988 under the leadership of the then Director of the Institute, National Prof. Brig. Abdul Malik as the Project Director. With his able leadership, the project was implemented with co-operation from the
Government of Japan through Japan International Co-operation Agency (JICA). Subsequently, the Government of Bangladesh incorporated this project into the revenue budget by giving it a permanent shape as National Center for Prevention of Rheumatic Fever and Heard Diseases.

The National Center for Prevention of Rheumatic Fever and Heard Diseases took up the operational programme by training Pediatricians, Cardiologists, Physicians, Epidemiologists, Microbiologists, Upazilla Health Officers and General Practitioners to detect and treat streptococcal sore throat. Nurses, paramedics and health assistants were also included within the scope of this training programme. Regional centers were setup in each division in the five old government medical colleges which also served greatly in the prevention of RF \& RHD at the community level.

Owing to the unique nature and pathogenesis of RF/RHD, both Individual and population strategies were adopted. While doctors were tasked with the secondary prevention in diagnosed cases of RF/RHD in both Inpatient and outpatient settings, nurses and paramedics were tasked alongside the doctors with primary prevention by identifying possible cases of streptococcal sore throat and administering primary prophylaxis as recommended by WHO. An 'Easy for All' method to identify cases of possible streptococcal sore throat was to detect cases of sore throat that were accompanied with

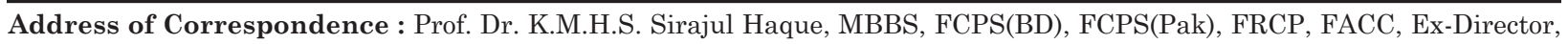
National Centre for Control of Rheumatic Fever \& Heart Diseases, Dhaka, Former Chairman- Department of Cardiology, Ex-DeanFaculty of Medicine, Bangabandhu Sheikh Mujib Medical University, Dhaka. 
fever, arthritis/arthralgia and the absence of running nose and eye congestion- the characteristics of viral sore throat. These suspected cases were then treated with benzathine penicillin, I/M-single shot (after skin test) or phenoxymethyl penicillin, orally, every 6 hours for 10 days. The oral regimen became especially popular with mothers and children owing to easy-painless administration and cost effectiveness.

The secondary prophylaxis included the administration of benzathine penicillin, IM (after skin test) every 21 days or phenoxymethyl penicillin, orally, every 12 hours till the age of 21 or for 5 years, whichever was longer in cases diagnosed as RF. In cases of RHD, the same antibiotics were continued for life.

The key to success of the programme lay in community participation which was achieved through organized leadership, multidisciplinary approach, adequate Government and International support and teamwork between healthcare practitioners and community leaders.

\section{References:}

1. Malik A. Congenital and Acquired Heart Diseases (A Survey of 7062 Persons). BMRC Bull 1976; 2:115-119.
2. Echocardiographic Analysis of 6600 cardiac cases in Bangladesh; Proceedings of the 2nd Bangladesh-Japan Conference on Cardiovascular disease, 1986.

3. Mahmud RS, Haque KMHSS, Sohrabuzzaman APM, et al. Unmasking Quiscent Carditis in Acute Rheumatic Fever by Color Flow And Doppler Echocardiography. 11th APCC, September 1995: 52.

4. Proceedings Of First National Scientific Conference On Rheumatic Fever And Rheumatic Heart Disease- Pilot Project for Control of RF \& RHD in Bangladesh; MOHFW, JICA; May 1992; Dhaka, Bangladesh.

5. Proceedings Of Second National Scientific Conference on Rheumatic Fever And Rheumatic Heart Disease- Pilot Project for Control of RF \& RHD in Bangladesh; MOHFW, JICA; May 1993; Dhaka, Bangladesh.

6. Rheumatic Fever, MTP Press Ltd., England; Taranta A. and Markowitz M.; p 60.

7. WHO Study Group. Rheumatic Fever and Rheumatic Heart Disease. WHO Technical Report Series No. 764. Geneva: World Health Organization; 1988

8. Mohibullah AKM. Juvenile Mitral Stenosis in Bangladesh (MD. Thesis). Dhaka: University of Dhaka. 1987: 58.

9. Majumder AAS, Flora MS, Islam AKMM, Shahidullah M, Zafar MA, Kahnom R, et al. Prevalence of Rheumatic Fever and Rheumatic Heart Disease in School Children of Bharateswari Homes of Bangladesh. Cardiovasc j 2014; 6(2): 103-106.

10. Zaman MM, Ahmed J. Prevalence of Rheumatic Fever and Rheumatic Heart Disease in Bangladeshi Children. Indian Heart J 2015; 67(1): 45-49. 